\title{
Effect of a single bolus of methylene blue prophylaxis on vasopressor and transfusion requirement in infective endocarditis patients undergoing cardiac surgery
}

\author{
Jin Sun $\mathrm{Cho}^{1}$, Jong Wook Song ${ }^{1,2}$, Sungwon $\mathrm{Na}^{1,2}$, Joo-Hwa Moon ${ }^{1}$, and Young Lan Kwak ${ }^{1,2,3}$ \\ ${ }^{1}$ Department of Anesthesiology and Pain Medicine, ${ }^{2}$ Anesthesia and Pain Research Institute, ${ }^{3}$ Severance Biomedical Science Institute, \\ Yonsei University College of Medicine, Seoul, Korea
}

Background: The accentuated nitric oxide (NO) release that is induced by the systemic inflammatory response associated with infective endocarditis (IE) and cardiopulmonary bypass (CPB) may result in catecholamine refractory hypotension (vasoplegia) and increased transfusion requirement due to platelet inhibition. Methylene blue (MB) is an inhibitory drug of inducible NO. We aimed to evaluate the effect of prophylactic MB administration before CPB on vasopressor and transfusion requirements in patients with IE undergoing valvular heart surgery (VHS).

Methods: Forty-two adult patients were randomly assigned to receive $2 \mathrm{mg} / \mathrm{kg}$ of MB (MB group, $\mathrm{n}=21$ ) or saline (control group, $\mathrm{n}=21$ ) for 20 min before the initiation of CPB. The primary end points were comparisons of vasopressor requirements serially assessed after weaning from $\mathrm{CPB}$ and hemodynamic parameters serially recorded before and after $\mathrm{CPB}$. The secondary endpoint was the comparison of transfusion requirements.

Results: Two patients in the control group received MB after weaning from CPB due to norepinephrine and vasopressin refractory vasoplegia and were thus excluded. There were no significant differences in vasopressor requirements and hemodynamic parameters between the two groups. The mean number of units of packed erythrocytes transfused per transfused patient was significantly less in the MB group. The numbers of patients transfused with fresh frozen plasma and platelet concentrates were less in the MB group.

Conclusions: In IE patients undergoing VHS, prophylactic MB administration before CPB did not confer significant benefits in terms of vasopressor requirements and hemodynamic parameters, but it was associated with a significant reduction in transfusion requirement. (Korean J Anesthesiol 2012; 63: 142-148)

Key Words: Cardiopulmonary bypass, Infective endocarditis, Methylene blue, Vasoplegia.

Received: October 28, 2011. Revised: 1st, December 27, 2011; 2nd, February 1, 2012; 3rd, February 16, 2012. Accepted: February $17,2012$. Corresponding author: Young Lan Kwak, M.D., Ph.D., Department of Anesthesiology and Pain Medicine, Anesthesia and Pain Research Institute, Severance Biomedical Science Institute, Yonsei University College of Medicine, 50, Yonsei-ro, Seodaemun-gu, Seoul 120-752, Korea. Tel: 82-2-2228-8513, Fax: 82-2-364-2951, E-mail: ylkwak@yuhs.ac

(c) This is an open-access article distributed under the terms of the Creative Commons Attribution Non-Commercial License (http:// creativecommons.org/licenses/by-nc/3.0/), which permits unrestricted non-commercial use, distribution, and reproduction in any medium, provided the original work is properly cited. 


\section{Introduction}

Infective endocarditis (IE) is a life-threatening disease that is associated with severe valvular dysfunction which occasionally requires surgical correction as a definite treatment $[1,2]$. IE produces a broad spectrum of systemic signs and symptoms related to systemic inflammatory response and endothelial nitric oxide (NO) release [2]. NO is associated with arterial vasodilatation and high cardiac output, and with decreased sensitivity of the heart and peripheral vessels to sympathomimetic agents [1]. In addition, NO is a potent inhibitor of platelet adhesion and aggregation [3]. Moreover, the process of valvular heart surgery (VHS) with cardiopulmonary bypass (CPB) may exacerbate pre-existing systemic inflammatory response [4], which will result in a profound reduction in systemic vascular resistance (SVR) and vasodilatory shock. This is an important issue in perioperative anesthetic management $[5,6]$.

Thus, patients with IE who are undergoing cardiac surgery are potentially at increased risk of refractory hypotension related to vasoplegia and bleeding complications.

Methylene blue (MB) has been used as an inhibitory drug of NO to treat refractory hypotension in anaphylaxis, septic shock and after CPB [6-8]. MB prevents elevation of the level of cyclic guanosine 3' 5 '-monophosphate (cGMP) by inhibiting guanylate cyclase, thereby blocking the cGMP-dependent vasodilatory effects of NO [9]. In patients with septic shock, MB effectively increased arterial blood pressure, SVR, and left ventricular stroke work without significant impact on cardiac output, oxygen delivery, and/or oxygen consumption [10]. Furthermore, the proper use of MB for the treatment of vasoplegic shock could reduce mortality and morbidity in patients undergoing cardiac surgery $[6,7,11]$. Regarding IE, there have been case reports of successful management of the refractory hypotension caused by IE with MB [1,12], but a prospective study of the use of MB in IE patients undergoing VHS has not yet been conducted.

In this prospective double blinded and randomized trial, we aimed to evaluate the effect of prophylactic MB administration before CPB on the use of vasopressors and hemodynamic parameters in patients with IE undergoing VHS. Additionally, transfusion requirements were also compared, considering the effect of MB on platelet function.

\section{Materials and Methods}

After IRB approval and receiving patients' consent, forty two patients with IE scheduled for VHS were included in this prospective, randomized study. All patients were treated with antibiotics for more than four weeks and were scheduled for surgery electively. Patients with positive blood cultures or signs of active inflammation including fever $\left(>38^{\circ} \mathrm{C}\right)$ or leukocytosis (white blood cell count $>11 \times 10^{3} / \mu \mathrm{l}$ ) were excluded [13] In addition, patients with ASA classification $>4$, preexisting lung parenchymal disease, severe hepatic or renal disease, cerebrovascular disease or coronary artery disease requiring surgical revascularization were also excluded. After induction, patients were randomly assigned to either the control group ( $\mathrm{n}=$ $21)$ or the MB group $(n=21)$ using a computerized randomized table. In the MB group, $2 \mathrm{mg} / \mathrm{kg}$ of MB was infused for $20 \mathrm{~min}$ before the start of CPB. In the control group, an equivalent volume of normal saline was infused instead of MB. To ensure blinding, the drugs were prepared by an anesthesiology nurse who was not involved in the study. Since the MB has a blue color, syringes were wrapped in aluminum foil. Cardiac surgeons and attending anesthesiologists were also blinded to the assigned group until the end of statistical analysis.

All cardiac medications except diuretics were continued until the day of surgery. Radial and pulmonary artery catheters were inserted under local anesthesia before anesthetic induction. Anesthesia was induced with intravenous midazolam (0.03-0.07 $\mathrm{mg} / \mathrm{kg})$, sufentanil (1.5-3.0 $\mu \mathrm{g} / \mathrm{kg}$ ) and rocuronium (0.9 mg/ $\mathrm{kg}$ ). After tracheal intubation, patients' lungs were mechanically ventilated with $40 \%$ oxygen with air to maintain normocarbia $\left(\mathrm{PaCO}_{2} 35 \pm 5 \mathrm{mmHg}\right)$. Anesthesia was maintained with sufentanil $(0.5-1.5 \mu \mathrm{g} / \mathrm{kg} / \mathrm{h})$, sevoflurane or isoflurane and vecuronium $(1-2 \mu \mathrm{g} / \mathrm{kg} / \mathrm{min})$. Persistent hypotension was treated with norepinephrine infusion before CPB.

All patients received standard surgical and CPB management. CPB was instituted with a membrane oxygenator. Body temperature was maintained under mild hypothermia (32$33^{\circ} \mathrm{C}$ ) and the $\alpha$-stat was used for acid-base management. Pump flow was maintained at a rate of $2.0-2.5 \mathrm{~L} / \mathrm{min} / \mathrm{m}^{2}$ using non-pulsatile flow, and a blood cardioplegic solution was used. During the perioperative period including $\mathrm{CPB}$, mean arterial blood pressure (MBP) was maintained at $55-80 \mathrm{mmHg}$ using norepinephrine or vasopressin. Norepinephrine was chosen as the primary vasopressor for treating systemic hypotension and vasopressin was added when the norepinephrine requirement exceeded $0.3 \mu \mathrm{g} / \mathrm{kg} / \mathrm{min}$. Milrinone was used if the left ventricular ejection fraction was lower than $30 \%$ (as measured by transesophageal echocardiography) after $\mathrm{CPB}$, in case of right ventricular dysfunction or pulmonary hypertension (a mean pulmonary arterial pressure [MPAP] greater than $50 \mathrm{mmHg}$ ). The criteria for transfusion of packed red blood cells (pRBC) were a hematocrit level below $21 \%$ during CPB and below $25 \%$ during the remaining perioperative period. Fresh frozen plasma (FFP) was transfused when the international normalized ratio was greater than 1.5 with excessive bleeding greater than 200 $\mathrm{ml} / \mathrm{h}$ for two consecutive hours in the postoperative period. 
Platelet concentrates (PLT) were transfused when the platelet count was less than $50,000 / \mathrm{mm}^{3}$ with excessive bleeding above $200 \mathrm{ml} / \mathrm{h}$ for two consecutive hours in the postoperative period.

Hemodynamic variables were recorded, including MBP, heart rate (HR), MPAP, central venous pressure (CVP), pulmonary capillary wedge pressure (PCWP), cardiac index (CI) and SVR $(80 \times[\mathrm{MBP}-\mathrm{CVP}] /$ cardiac output $)$. Measurements were performed before CPB (baseline), 20 minutes after weaning from CPB (T2), at sternum closure (T3), and immediately after (T4) and 12 hours after intensive care unit (ICU) arrival (T5). Vasopressor and milrinone requirements were assessed at the same time points excluding that before $\mathrm{CPB}$, when none of the patients required any vasopressor or milrinone. Thus, their requirements were assessed immediately after weaning from CPB (T1) and at T2, T3, T4 and T5.

All patients were transferred to ICU after surgery, and received standard management according to institutional guidelines by the ICU staff consisting of anesthesiologists and a cardiac surgeon not involved in this study. Postoperative fluid management was performed to keep PCWP between 10 and $14 \mathrm{mmHg}, \mathrm{CI}>2 \mathrm{~L} / \mathrm{min} / \mathrm{m}^{2}$, and urinary output $>$ $0.5 \mathrm{ml} / \mathrm{kg} / \mathrm{h}$. The length of stay in ICU and the duration of postoperative hospitalization were recorded. In addition, major morbidity endpoints including renal failure (new increase of serum creatinine $>2.0 \mathrm{mg} / \mathrm{dl}$ or $>50 \%$ over baseline or a new requirement for dialysis), cerebrovascular event, deep sternal wound infection, ventilator care $>48 \mathrm{~h}$ and/or hemostatic reoperation were recorded by anesthesiologists not aware of this study [14]. Hemostatic reoperation was indicated when chest tube drainage was greater than $200 \mathrm{ml} / \mathrm{h}$ for six consecutive hours or greater than $400 \mathrm{ml}$ during the first hour despite a normalized activated clotting time and global coagulation status. Decisions for extubation and discharge from the ICU were also made according to institutional guidelines at the discretion of the ICU staff, as described elsewhere [15].

\section{Statistical analysis}

All statistical analyses were performed using SPSS (SPSSFW, SPSS Inc., Chicago, IL, USA). The primary end point of this study was to evaluate the amount of infused norepinephrine during and after СРB. A difference of $0.1 \mu \mathrm{g} / \mathrm{kg} / \mathrm{min}$ in the norepinephrine infusion rate between the groups was taken as clinically significant. Based on the institutional results for IE patients who underwent VHS, the standard deviation of norepinephrine infusion was $0.1 \mu \mathrm{g} / \mathrm{kg} / \mathrm{min}$. This calculation generated an estimated 18 patients in each group with $80 \%$ power and an alpha level of 0.05 . Considering the $10 \%$ of dropout rate, 20 patients in each group were enrolled. All data were expressed as the number of patients or the mean \pm SD. The normality of distribution was assessed using a q-q plot and the Shapiro-Wilk test. Between-group data was compared by the $\chi^{2}$ test, Fisher's exact test, independent t-test with post hoc comparison using the Bonferroni test or Mann-Whitney U test with same post hoc comparison as appropriate. Continuous variables were presented as mean \pm SD or median [interquartile range], and dichotomous variables were presented as number. A P value $<0.05$ was considered as significant.

\section{Results}

Two patients demonstrated refractory hypotension despite norepinephrine and vasopressin infusion. They were revealed as patients in the control group and MB was infused after CPB. After MB administration, their blood pressure was successfully restored to the predefined target range. The data of these two patients were excluded from statistical analysis.

Patient characteristics were similar between the two groups, apart from the fact that the number of patients with hypertension was significantly higher in the control group than in the MB group. The type of valvular surgery performed, and the duration of CPB and aortic cross clamp were not statistically different between groups (Table 1).

Table 1. Patient Characteristics

\begin{tabular}{lccc}
\hline & $\begin{array}{c}\text { Control } \\
(\mathrm{n}=19)\end{array}$ & $\begin{array}{c}\text { MB } \\
(\mathrm{n}=21)\end{array}$ & P value \\
\hline Age (yr) & $47.6 \pm 20.7$ & $42.8 \pm 11.4$ & 0.362 \\
Sex (M/F) & $14 / 5$ & $12 / 9$ & 0.273 \\
Height (cm) & $168.2 \pm 8.8$ & $167.2 \pm 7.6$ & 0.698 \\
Weight (kg) & $56.9 \pm 14.3$ & $59.6 \pm 10.8$ & 0.501 \\
Diabetes mellitus (n) & 2 & 3 & 0.720 \\
Hypertension (n) & 8 & $1^{*}$ & 0.005 \\
Pre-operative LVEF (\%) & $68.5 \pm 8.2$ & $66.9 \pm 11.2$ & 0.607 \\
Pre-operative medications & & & \\
$\quad \beta$-blockers (n) & 3 & 3 & 0.894 \\
Calcium channel blockers (n) & 4 & 4 & 0.874 \\
Renin angiotensin inhibitors (n) & 8 & 10 & 0.726 \\
Nitrate (n) & 0 & 1 & 0.335 \\
Sigmart (n) & 0 & 1 & 0.335 \\
Digoxin (n) & 2 & 4 & 0.451 \\
$\quad$ Diuretics (n) & 11 & 15 & 0.370 \\
Operation & & & \\
$\quad$ Mitral valve replacement (n) & 14 & 18 & 0.342 \\
Aortic valve replacement (n) & 9 & 7 & 0.366 \\
Tricuspid annuloplasty (n) & 2 & 1 & 0.489 \\
$\quad$ Coronary artery bypass graft (n) & 2 & 1 & 0.489 \\
Duration of ACC (min) & $76.5 \pm 25.9$ & $76.0 \pm 26.9$ & 0.960 \\
Duration of CPB (min) & $102.5 \pm 26.6$ & $106.0 \pm 30.5$ & 0.697 \\
\hline Valus ar number & & &
\end{tabular}

Values are number or mean \pm standard deviation. LVEF: left ventricular ejection fraction, ACC: aortic cross clamp, CPB: cardiopulmonary bypass, $\mathrm{MB}$ : patients received $2 \mathrm{mg} / \mathrm{kg}$ of methylene blue was infused for $20 \mathrm{~min}$ before the start of $\mathrm{CPB}$, Control: patients received equivalent amount of normal saline was infused at the same time. $* \mathrm{P}<0.05$ compared to the control group. 
The hemodynamic variables, including MBP, HR, MPAP, CVP, PCWP, CI and SVR, were similar in both groups throughout the study period (Table 2).

The required amount of vasopressor and the number of patients requiring vasopressors or an inotropic agent during weaning from $\mathrm{CPB}$ and the postoperative period were not statistically different between the groups (Table 3).

Until 24 hours after the operation, the mean number of units of pRBC trasnfused per transfused patient was significantly less in the MB group, although the number of patients transfused

Table 2. Changes in Hemodynamic Variables

\begin{tabular}{|c|c|c|c|c|c|}
\hline & Baseline & $\mathrm{T} 2$ & T3 & $\mathrm{T} 4$ & T5 \\
\hline \multicolumn{6}{|c|}{ MBP (mmHg) } \\
\hline Control & $68.2 \pm 12.5$ & $67.8 \pm 11.2$ & $68.3 \pm 7.6$ & $77.6 \pm 13.7$ & $74.5 \pm 8.1$ \\
\hline $\mathrm{MB}$ & $72.4 \pm 10.1$ & $61.7 \pm 10.8$ & $64.3 \pm 6.4$ & $78.6 \pm 12.7$ & $76.1 \pm 12.3$ \\
\hline \multicolumn{6}{|c|}{ Heart rate (beats/min) } \\
\hline Control & $78.4 \pm 14.1$ & $91.2 \pm 12.9$ & $95.2 \pm 12.5$ & $93.8 \pm 11.5$ & $85.6 \pm 12.4$ \\
\hline MB & $83.1 \pm 19.2$ & $89.0 \pm 13.0$ & $93.2 \pm 15.2$ & $94.1 \pm 15.6$ & $85.2 \pm 12.8$ \\
\hline \multicolumn{6}{|c|}{ CVP (mmHg) } \\
\hline Control & $8.5 \pm 3.8$ & $8.5 \pm 2.3$ & $9.8 \pm 3.2$ & $7.7 \pm 3.0$ & $8.9 \pm 2.1$ \\
\hline MB & $9.3 \pm 4.7$ & $9.3 \pm 1.7$ & $10.5 \pm 1.8$ & $9.1 \pm 2.9$ & $8.5 \pm 2.2$ \\
\hline \multicolumn{6}{|c|}{ MPAP (mmHg) } \\
\hline Control & $24.9 \pm 10.2$ & $18.9 \pm 4.1$ & $19.1 \pm 5.7$ & $18.1 \pm 3.5$ & $17.4 \pm 2.5$ \\
\hline MB & $30.4 \pm 13.3$ & $20.3 \pm 4.4$ & $20.9 \pm 4.7$ & $20.3 \pm 6.4$ & $18.0 \pm 5.4$ \\
\hline \multicolumn{6}{|c|}{ PCWP (mmHg) } \\
\hline Control & $18.3 \pm 7.7$ & $13.7 \pm 3.7$ & $14.7 \pm 3.4$ & $12.9 \pm 2.7$ & $12.7 \pm 2.1$ \\
\hline MB & $22.5 \pm 11.2$ & $14.7 \pm 4.0$ & $15.3 \pm 4.4$ & $15.0 \pm 5.1$ & $13.5 \pm 4.8$ \\
\hline \multicolumn{6}{|c|}{$\mathrm{CI}\left(\mathrm{L} / \mathrm{m}^{2} / \mathrm{min}\right)$} \\
\hline Control & $2.7 \pm 0.6$ & $3.4 \pm 0.6$ & $3.4 \pm 0.7$ & $3.8 \pm 1.3$ & $3.3 \pm 0.7$ \\
\hline MB & $2.8 \pm 0.9$ & $3.4 \pm 0.6$ & $3.5 \pm 0.9$ & $3.5 \pm 1.0$ & $2.9 \pm 0.6$ \\
\hline \multicolumn{6}{|c|}{ SVR (dynes.sec/ $/ \mathrm{cm}^{5}$ ) } \\
\hline Control & $1,175 \pm 318$ & $916 \pm 268$ & $948 \pm 249$ & $960 \pm 304$ & $1,071 \pm 286$ \\
\hline $\mathrm{MB}$ & $1,185 \pm 376$ & $843 \pm 326$ & $870 \pm 343$ & $1,085 \pm 540$ & $1,138 \pm 330$ \\
\hline
\end{tabular}

Values represent mean \pm standard deviation. Baseline: pre-cardiopulmonary bypass, T2: 20 min after weaning from cardiopulmonary bypass, T3: sternum closure, T4: at intensive care unit arrival, T5: $12 \mathrm{hr}$ after weaning from cardiopulmonary bypass, MBP: mean blood pressure, CVP: central venous pressure, MPAP: mean pulmonary arterial pressure, PCWP: pulmonary capillary wedge pressure, CI: cardiac index, SVR: systemic vascular resistance. MB: patients received $2 \mathrm{mg} / \mathrm{kg}$ of methylene blue, infused for 20 min before the start of cardiopulmonary bypass, Control: patients received an equivalent amount of normal saline, infused at the same time. All P values of intergroup comparisons were above 0.05 .

Table 3. Perioperative Vasopressor and Milrinone Requirement

\begin{tabular}{|c|c|c|c|c|c|}
\hline & $\mathrm{T} 1$ & $\mathrm{~T} 2$ & T3 & $\mathrm{T} 4$ & T5 \\
\hline \multicolumn{6}{|l|}{ Norepinephrine } \\
\hline Control $(\mu \mathrm{g} / \mathrm{kg} / \mathrm{min})$ & $0.09(0.05-0.17)$ & $0.06(0-0.17)$ & $0.07(0-0.20)$ & $0.02(0-0.05)$ & $0(0-0.01)$ \\
\hline $\mathrm{MB}(\mu \mathrm{g} / \mathrm{kg} / \mathrm{min})$ & $0.06(0.01-0.14)$ & $0.05(0-0.16)$ & $0(0-0.09)$ & $0.02(0-0.04)$ & $0(0-0.01)$ \\
\hline Control (n) & 14 & 14 & 14 & 12 & 10 \\
\hline $\mathrm{MB}(\mathrm{n})$ & 13 & 18 & 15 & 15 & 10 \\
\hline \multicolumn{6}{|l|}{ Vasopressin } \\
\hline Control (u/h) & $0(0-4)$ & $0(0-0)$ & $0(0-1.8)$ & $0(0-2)$ & $0(0-0)$ \\
\hline $\mathrm{MB}(\mathrm{u} / \mathrm{h})$ & $0(0-3)$ & $0(0-0)$ & $0(0-4)$ & $0(0-2.8)$ & $0(0-0)$ \\
\hline Control (n) & 7 & 5 & 7 & 7 & 1 \\
\hline $\mathrm{MB}(\mathrm{n})$ & 4 & 7 & 12 & 7 & 2 \\
\hline \multicolumn{6}{|l|}{ Milrinone } \\
\hline Control $(\mu \mathrm{g} / \mathrm{kg} / \mathrm{min})$ & $0(0-0.41)$ & $0(0-0)$ & $0(0-0)$ & $0(0-0.41)$ & $0(0-0.39)$ \\
\hline $\mathrm{MB}(\mu \mathrm{g} / \mathrm{kg} / \mathrm{min})$ & $0(0-0.5)$ & $0(0-0)$ & $0(0-0)$ & $0(0-0.31)$ & $0(0-0.47)$ \\
\hline Control (n) & 5 & 5 & 5 & 6 & 8 \\
\hline $\mathrm{MB}(\mathrm{n})$ & 6 & 9 & 9 & 8 & 9 \\
\hline
\end{tabular}

Values are the number or median (interquartile range). T1: immediately after weaning from cardiopulmonary bypass, T2: 20 min after weaning from cardiopulmonary bypass, T3: sternum closure, T4: at intensive care unit arrival, T5: 12 hr after weaning from cardiopulmonary bypass. MB: patients received $2 \mathrm{mg} / \mathrm{kg}$ of methylene blue,infused for $20 \mathrm{~min}$ before the start of cardiopulmonary bypass, Control: patients received an equivalent amount of normal saline infused at the same time. All $\mathrm{P}$ values of intergroup comparisons were above 0.05 . 
Table 4. In-hospital Postoperative Outcomes

\begin{tabular}{|c|c|c|c|}
\hline & Control $(n=19)$ & $\operatorname{MB}(\mathrm{n}=21)$ & $P$ value \\
\hline Postoperative $24 \mathrm{hr}$ blood loss (ml) & $502.9 \pm 514.7$ & $483.8 \pm 345.7$ & 0.890 \\
\hline \multicolumn{4}{|l|}{ Postoperative $24 \mathrm{hr}$ transfusion } \\
\hline pRBC transfused patients (n) & 7 & 7 & 0.816 \\
\hline pRBC units/transfused patients & $4.6 \pm 2.9$ & $1.6 \pm 0.5^{*}$ & 0.019 \\
\hline FFP transfused patients (n) & 8 & $3 *$ & 0.049 \\
\hline FFP units/transfused patients & $4.6 \pm 4.0$ & $2.0 \pm 1.0$ & 0.308 \\
\hline PLT transfused patients (n) & 5 & 1 & 0.057 \\
\hline PLT units/transfused patients & $6.2 \pm 4.1$ & 8 & 0.712 \\
\hline Major morbidity endpoints & 9 & 6 & 0.220 \\
\hline Renal failure (n) & 2 & 2 & 0.916 \\
\hline Ventilator care $>48 \mathrm{~h}(\mathrm{n})$ & 2 & 2 & 0.916 \\
\hline Cerebrovascular event (n) & 1 & 0 & 0.287 \\
\hline Deep sternal wound infection (n) & 1 & 0 & 0.287 \\
\hline Hemostatic reoperation (n) & 1 & 0 & 0.287 \\
\hline Duration of ICU stay (d) & $4.7 \pm 4.9$ & $3.8 \pm 2.0$ & 0.433 \\
\hline Duration of hospital stay (d) & $21.8 \pm 8.8$ & $18.4 \pm 7.6$ & 0.199 \\
\hline
\end{tabular}

Values are number or mean \pm standard deviation. pRBC: packed red blood cell, FFP: fresh frozen plasma, PLT: platelet concentrate, ICU: intensive care unit. MB: patients received $2 \mathrm{mg} / \mathrm{kg}$ of methylene blue, infused for 20 min before the start of cardiopulmonary bypass, Control: patients received an equivalent amount of normal saline, infused at the same time. $* \mathrm{P}<0.05$ compared to the control group.

with pRBC was not different between the groups. The number of patients transfused with FFP $(\mathrm{P}=0.049)$ and PLT $(\mathrm{P}=0.057)$ was smaller in the $\mathrm{MB}$ group while the mean number of units of transfused FFP and PLT per transfused patient were not different. The incidences of assessed major morbidity endpoints were all similar between the groups. The durations of ICU and hospital stays were also similar between the groups (Table 4).

\section{Discussion}

In this prospective, randomized and controlled trial, prophylactic MB administration before $\mathrm{CPB}$ did not provide significant benefit in terms of vasopressor requirement in IE patients undergoing VHS, while MB partially conferred a beneficial effect on perioperative transfusion requirement.

The incidence of IE is approximately $1.7-6.2$ cases per 100,000 patients [16]. While dental surgery was the main cause of IE in the past, it is now more likely related to previous VHS, degenerative valve disease, and nosocomial infection [17]. Most of the morbidities and mortality associated with IE are related to valvular dysfunction and abscess formation secondary to tissue destruction, heart failure and embolic events. VHS is required in approximately $50 \%$ of IE patients and can be a definite treatment, while the timing of operation plays an important role in patient outcomes [2]. In a patient with a stable medical condition, the operation can be delayed after antibiotic treatment in order to reduce the risk of preoperative complications and early prosthetic valve endocarditis. However, emergent operation should be considered if hemodynamic compromise, persistent infection despite appropriate antibiotic treatment, or large vegetations with high embolic potential are suspected [2].

In IE, bacterial endotoxin stimulates different types of cells to release cytokines and inflammatory mediators that activate the inducible nitric oxide synthase (iNOS), which increases the production of NO. NO in turn stimulates the production of cGMP. Excessive formation of NO and cGMP is related to profound vasodilatation, myocardial depression, and decreased response to catecholamines. Thus IE is associated with a systemic inflammatory response and frequent low SVR syndrome (vasoplegic syndrome, VS) [1], which is clinically expressed as severe hypotension or shock without response to volume expansion and which requires large amounts of vasopressor to maintain normotension. Furthermore, $\mathrm{CPB}$ during VHS may exacerbate the systemic inflammatory response, thereby predisposing the patients with IE to VS [6].

The important roles of NO in systemic inflammatory response and VS in IE patients undergoing VHS encourage the prophylactic use of NO-inhibitory drugs such as MB. For several decades, MB has been used to treat VS through inhibiting the vasodilatory effect of NO and other nitrovasodilators on the endothelium and vascular smooth muscle $[7,18]$. In a clinical study recruiting 638 patients undergoing elective cardiac surgery, MB (1.5 mg/ $\mathrm{kg}$ ) administered in patients with VS after CPB significantly lowered morbidity ( $0 \%$ vs. $21.4 \%$ ) and resulted in a shorter postoperative recovery time [7], however, patients with IE were excluded from this study. Regarding septic endocarditis, there was a case report that administration of MB during CPB reversed refractory hypotension by increasing SVR and reducing vasopressor requirement in an adult patient [1]. In 
that case, a bolus of $\mathrm{MB}(2 \mathrm{mg} / \mathrm{kg})$ before $\mathrm{CPB}$ was followed by continuous infusion $(0.5-1 \mathrm{mg} / \mathrm{kg} / \mathrm{h})$ during and $30 \mathrm{~min}$ after CPB. On the contrary, in a case of pediatric patient with mitral valve endocarditis demonstrating refractory hypotension, $\mathrm{MB}$ was less effective than expected despite the use of same dosing regimen and protocol, and other vasopressor supports were required [12]. The influence of prophylactically administered $\mathrm{MB}$ before $\mathrm{CPB}$ on the occurrence of VS and the vasopressor requirement in patients with IE has not previously been addressed.

Despite the above mentioned theoretical background, however, we could not observe any beneficial effects of prophylactic $\mathrm{MB}$ in terms of the amount of vasopressor requirement and hemodynamic parameters including SVR in the current study. There is currently no standardized MB administration protocol for the prevention or reversal of VS. MB has been administered preoperatively, before $\mathrm{CPB}$, during $\mathrm{CPB}$, and postoperatively $[1,7,12,18,19]$. Dosing for the treatment of VS has been reported to be variable, from 1.5 to $3 \mathrm{mg} / \mathrm{kg}$ up to as much as $7 \mathrm{mg} / \mathrm{kg}$, and has been administered as an intravenous bolus with or without continuous infusion [7,12,20,21], while a loading of $2 \mathrm{mg} / \mathrm{kg}$ of $\mathrm{MB}$ for $20 \mathrm{~min}$ has been most commonly used. MB is not free of side effects: the most commonly reported adverse effects include cardiac arrhythmia, angina, decreased cardiac output, renal blood flow, resistance and a deterioration in gas exchange. These effects have been reported to usually occur at a dose of more than $2 \mathrm{mg} / \mathrm{kg}$ of MB. In addition, hemolytic anemia and hyperbilirubinemia has been reported with $\mathrm{MB}$ administration in doses in excess of $2 \mathrm{mg} / \mathrm{kg}$, although occurrence has been rare [22,23]. Thus, we decided to administer a bolus of $2 \mathrm{mg} / \mathrm{kg}$ of $\mathrm{MB}$ without continuous infusion in this study. However, as the plasma concentration of MB sharply declines during the first $40 \mathrm{~min}$ after a bolus [24], continuous infusion in the next hours could have been helpful to maintain the therapeutic concentration during the perioperative period and may have conveyed different results. In pediatric patients, however, MB failed to improve hemodynamic profiles despite being administered as a bolus ( 2 $\mathrm{mg} / \mathrm{kg}$ ) before $\mathrm{CPB}$ and then continuously infused $(0.5-1 \mathrm{mg} /$ $\mathrm{kg} / \mathrm{h}$ ) during and after CPB [12].

Other possible reasons for the absence of beneficial effect of $\mathrm{MB}$ in the current study are as follows. Firstly, preoperative uses of angiotensin converting enzyme (ACE) inhibitors, calcium channel blockers (CCB) and heparin are known risk factors of VS in cardiac surgical patients. In the current study, most patients were treated with ACE inhibitors, CCB and heparin preoperatively in addition to IE itself. The concomitant use of these medications may have resulted in marked vasodilation, which may have been so overwhelming as to mask the preventive effect of a MB bolus. Secondly, it has been reported that a window of opportunity for MB efficacy exists in terms of helping to restore SVR, depending on the activity of soluble guanylate cyclase [21]. In a septic model, coincident with increased iNO expression, guanylate cyclase expression was exhausted due to excessive NO production and lack of counteraction of MB was observed [21]. Therefore, there is a possibility that guanylate cyclase may have been exhausted due to excessive activation of inflammatory system in IE patients, and thus MB could not confer beneficial influence. In the current study, two patients in the control group received $\mathrm{MB}$ after CPB because of excessive vasopressor requirement and interestingly, MB infusion successfully reversed refractory hypotension in these patients. This may be attributable to the fact that these patients were in the window of opportunity during which guanylate cylases were resynthesized, and MB could be effective again. As major hemodynamic variables such as $\mathrm{CI}, \mathrm{MBP}$ and filling pressures were intended to be maintained within the predefined target range, the lack of difference in hemodynamic parameters including SVR is not surprising. Yet, the lack of difference in vasopressor requirements in order to achieve a certain hemodynamic goal precludes any conclusive benefit of prophylactic MB administration in terms of hemodynamic management. Therefore, more studies addressing the optimal timing and regimen of MB for the treatment of VS in IE patients undergoing VHS seem to be required.

NO was reported to be involved in the pathogenesis of the bleeding tendency as a potent inhibitor of platelet adhesion and aggregation [3]. In one animal study, $\mathrm{N}$-monimethyl-Larginine, an inhibitor of NO formation from L-arginine, completely normalized the bleeding time in rats with renal mass reduction and uremia with bleeding tendency [25]. Systemic inhibition of NO production also shortened bleeding time in humans [26]. In the current study, there was a distinct trend toward significantly fewer patients requiring FFP and PLT transfusion during postoperative 24 hours in the MB group. Furthermore, although the number of patients transfused with pRBC was similar, the amount of pRBC transfused per patient was significantly less. These results are in agreement with the result of a previous study that demonstrated a reduction in the amount of transfusion in an MB group in coronary artery bypass graft surgery patients [19]. Similar postoperative blood loss between groups might be associated with the fact that the frequent use of FFP and PLT in the control group may have resulted in reduced late postoperative bleeding.

The limitation of this study is as follows. Inclusion of patients in the acute phase of IE would have revealed more definite results. However, cardiac surgery for IE is usually performed after stabilization with antibiotics treatment for as long as the patient's clinical condition permits. Accordingly, it would be challenging to enroll such patients in a sufficient number. Moreover, a study comparing stabilized IE patients with patients 
without IE undergoing the same VHS revealed that patients with IE had a significantly higher incidence of heparin resistance and a higher postoperative stroke rate. These patients also required significantly longer postoperative hospitalization, implying an adverse prognosis despite stabilization [13].

In conclusion, the preventive use of MB before CPB did not result in significant beneficial effects in terms of reducing perioperative vasopressor requirement and improving hemodynamic variables, but there were significant reductions in the incidence of FFP and PLT transfusion and a lower amount of pRBC transfusion per patient seen in the MB group. Considering its proven beneficial clinical effects, further evaluation of the proper administration protocol, including treatment timing and continuous infusion, seems to be warranted.

\section{References}

1. Grayling M, Deakin CD. Methylene blue during cardiopulmonary bypass to treat refractory hypotension in septic endocarditis. J Thorac Cardiovasc Surg 2003; 125: 426-7.

2. Beynon RP, Bahl VK, Prendergast BD. Infective endocarditis. BMJ 2006; 333: 334-9.

3. Smolenski A. Novel roles of cAMP/cGMP dependent signaling in platelets. J Thromb Haemost 2012; 10: 167-76.

4. Warren OJ, Smith AJ, Alexiou C, Rogers PL, Jawad N, Vincent C, et al. The inflammatory response to cardiopulmonary bypass: part 1--mechanisms of pathogenesis. J Cardiothorac Vasc Anesth 2009; 23: 223-31.

5. Mekontso-Dessap A, Houel R, Soustelle C, Kirsch M, Thebert D, Loisance DY. Risk factors for post-cardiopulmonary bypass vasoplegia in patients with preserved left ventricular function. Ann Thorac Surg 2001; 71: 1428-32.

6. Evora PR. Should methylene blue be the drug of choice to treat vasoplegias caused by cardiopulmonary bypass and anaphylactic shock?. J Thorac Cardiovasc Surg 2000; 119: 632-4.

7. Levin RL, Degrange MA, Bruno GF, Del Mazo CD, Taborda DJ, Griotti JJ, et al. Methylene blue reduces mortality and morbidity in vasoplegic patients after cardiac surgery. Ann Thorac Surg 2004; 77: 496-9.

8. Kirov MY, Evgenov OV, Evgenov NV, Egorina EM, Sovershaev MA, Sveinbjornsson B, et al. Infusion of methylene blue in human septic shock: a pilot, randomized, controlled study. Crit Care Med 2001; 29: 1860-7.

9. Daemen-Gubbels CR, Groeneveld PH, Groeneveld AB, van Kamp GJ, Bronsveld W, Thijs LG. Methylene blue increases myocardial function in septic shock. Crit Care Med 1995; 23: 1363-70.

10. Preiser JC, Lejeune P, Roman A, Carlier E, De Backer D, Leeman M, et al. Methylene blue administration in septic shock: a clinical trial. Crit Care Med 1995; 23: 259-64.

11. Yiu P, Robin J, Pattison CW. Reversal of refractory hypotension with single-dose methylene blue after coronary artery bypass surgery. J Thorac Cardiovasc Surg 1999; 118: 195-6.

12. Taylor K, Holtby H. Methylene blue revisited: management of hypotension in a pediatric patient with bacterial endocarditis. J Thorac Cardiovasc Surg 2005; 130: 566.

13. Na S, Shim JK, Chun DH, Kim DH, Hong SW, Kwak YL. Stabilized infective endocarditis and altered heparin responsiveness during cardiopulmonary bypass. World J Surg 2009; 33: 1862-7.

14. Shroyer AL, Coombs LP, Peterson ED, Eiken MC, DeLong ER, Chen A, et al. The Society of Thoracic Surgeons: 30-day operative mortality and morbidity risk models. Ann Thorac Surg 2003; 75: 1856-64.

15. Shim JK, Chun DH, Choi YS, Lee JY, Hong SW, Kwak YL. Effects of early vital capacity maneuver on respiratory variables during multivessel off-pump coronary artery bypass graft surgery. Crit Care Med 2009; 37: 539-44.

16. Mylonakis E, Calderwood SB. Infective endocarditis in adults. N Engl J Med 2001; 345: 1318-30.

17. Bouza E, Menasalvas A, Munoz P, Vasallo FJ, del Mar Moreno M, Garcia Fernandez MA. Infective endocarditis--a prospective study at the end of the twentieth century: new predisposing conditions, new etiologic agents, and still a high mortality. Medicine (Baltimore) 2001; 80: 298-307.

18. Stawicki SP, Sims C, Sarani B, Grossman MD, Gracias VH. Methylene blue and vasoplegia: who, when, and how? Mini Rev Med Chem 2008; 8: 472-90.

19. Ozal E, Kuralay E, Yildirim V, Kilic S, Bolcal C, Kucukarslan N, et al. Preoperative methylene blue administration in patients at high risk for vasoplegic syndrome during cardiac surgery. Ann Thorac Surg 2005; 79: 1615-9.

20. Maslow AD, Stearns G, Butala P, Schwartz CS, Gough J, Singh AK. The hemodynamic effects of methylene blue when administered at the onset of cardiopulmonary bypass. Anesth Analg 2006; 103: 2-8.

21. Evora PR, Ribeiro PJ, Vicente WV, Reis CL, Rodrigues AJ, Menardi $\mathrm{AC}$, et al. Methylene blue for vasoplegic syndrome treatment in heart surgery: fifteen years of questions, answers, doubts and certainties. Rev Bras Cir Cardiovasc 2009; 24: 279-88.

22. Shanmugam G. Vasoplegic syndrome--the role of methylene blue. Eur J Cardiothorac Surg 2005; 28: 705-10.

23. Del Duca D, Sheth SS, Clarke AE, Lachapelle KJ, Ergina PL. Use of methylene blue for catecholamine-refractory vasoplegia from protamine and aprotinin. Ann Thorac Surg 2009; 87: 640-2.

24. Peter C, Hongwan D, Kupfer A, Lauterburg BH. Pharmacokinetics and organ distribution of intravenous and oral methylene blue. Eur J Clin Pharmacol 2000; 56: 247-50.

25. Remuzzi G, Perico N, Zoja C, Corna D, Macconi D, Vigano G. Role of endothelium-derived nitric oxide in the bleeding tendency of uremia. J Clin Invest 1990; 86: 1768-71.

26. Simon DI, Stamler JS, Loh E, Loscalzo J, Francis SA, Creager MA. Effect of nitric oxide synthase inhibition on bleeding time in humans. J Cardiovasc Pharmacol 1995; 26: 339-42. 